\title{
Environmental, Health, and Safety Issues of Sodium-Sulfur Batteries for Electric and Hybrid Vehicles
}

\section{Volume IV: In-Vehicle Safety}

J. Mark

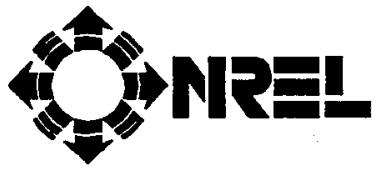

National Renewable Energy Laboratory

(formerly the Solar Energy Research Institute) 1617 Cole Boulevard Golden, Colorado 80401-3393

A Division of Midwest Research Institute Operated for the U.S. Department of Energy under Contract No. DE-AC02-83CH10093

Prepared under Task No. AS015440

November 1992 
On September 16, 1991 the Solar Energy Institute was designated a national laboratory, and its name was changed to the National Renewable Energy Laboratory.

\title{
NOTICE
}

This report was prepared as an account of work sponsored by an agency of the United States government. Neither the United States government nor any agency thereof, nor any of their employees, makes any warranty, express or implied, or assumes any legal liability or responsibility for the accuracy, completeness, or usefulness of any information, apparatus, product, or process disclosed, or represents that its use would not infringe privately owned rights. Reference herein to any specific commercial product, process, or senvice by trade name, trademark, manufacturer, or otherwise does not necessarily constitute or imply its endorsement, recommendation, or favoring by the United States government or any agency thereof. The views and opinions of authors expressed herein do not necessarily state or reflect those of the United States government or any agency thereof.

\author{
Printed in the United States of America \\ Available from: \\ National Technical Information Service \\ U.S. Department of Commerce \\ 5285 Port Royal Road \\ Springfield, VA 22161
}

Price: Microfiche A01

Printed Copy $\mathrm{AO3}$

Codes are used for pricing all publications. The code is determined by the number of pages in the publication. Information pertaining to the pricing codes can be found in the current issue of the following publications which are generally available in most libraries: Energy Research Abstracts (ERA); Government Reports Announcements and Index (GRA and I); Scientific and Technical Abstract Reports (STAR); and publication NTIS-PR-360 available from NTIS at the above address. 


\section{Preface}

This report is the last of four volumes that identify and assess the environmental, health, and safety issues that may affect the commercial-scale use of sodium-sulfur $(\mathrm{Na} / \mathrm{S})$ battery technology as the energy source in electric and hybrid vehicles. The reports are intended to help the Electric and Hybrid Propulsion Division of the Office of Transportation Technologies in the U.S. Department of Energy (DOE/EHP) determine the direction of its research, development, and demonstration (RD\&D) program for Na/S battery technology. ${ }^{1}$ The reports review the status of $\mathrm{Na} / \mathrm{S}$ battery $\mathrm{RD} \& \mathrm{D}$ and identify potential hazards and risks that may require additional research or that may affect the design and use of $\mathrm{Na} / \mathrm{S}$ batteries.

These reports were prepared by the Analytic Studies Division of the National Renewable Energy Laboratory and are one part of DOE/EHP's RD\&D program to work with industry to commercialize Na/S batteries. For example, data and information obtained through these reports will assist the DOE/EHP implement recommendations made by participants at government-industry meetings on sodium-beta batteries sponsored by the DOE/EHP [1]. The reports may also assist the DOE/EHP and the Ad Hoc Electric Vehicle Battery Readiness Working Group coordinate the RD\&D needed to commercialize $\mathrm{Na} / \mathrm{S}$ and sodium metal chloride battery technologies. ${ }^{2}$

For these reports, it is important to define hazard and risk. A hazard is a source of risk, a substance or action that can cause harm. Risk, on the other hand, is the possibility of suffering harm from a hazard [2]. While the chemical and thermal hazards of elemental sodium are substantial, the risks involved in using sodium in a battery can be minimized through careful design, engineering, and testing. These reports on $\mathrm{Na} / \mathrm{S}$ battery technology do not constitute a formal risk analysis, which usually includes estimates of the amounts, frequencies, and locations of the release of hazardous materials; the duration of exposures to these agents; estimates of the percentage of the population exposed and of dosage-response relationships; and a quantitative estimate of risk [2]. These reports provide a qualitative analysis of hazards and risks that must be addressed before $\mathrm{Na} / \mathrm{S}$ batteries can be deployed on a commercial scale. These reports are intended to help DOE/EHP set management priorities for the RD\&D of $\mathrm{Na} / \mathrm{S}$ battery technology by identifying potential hazards and risks, by reviewing RD\&D in progress to address these hazards and risks, and by recommending RD\&D needed to help minimize these hazards and risks.

This volume covers the in-vehicle safety issues of electric vehicles powered by $\mathrm{Na} / \mathrm{S}$ batteries. The report is based on a review of the literature and on discussions with experts at DOE, national laboratories and agencies, and private industry. It has three major goals: (1) to identify the unique hazards associated with electric vehicle (EV) use; (2) to describe the existing standards, regulations, and guidelines that are or could be applicable to these hazards; and (3) to discuss the adequacy of the existing requirements in addressing the safety concerns of EVs.

\footnotetext{
${ }^{1}$ These assessments are concemed with $\mathrm{Na} / \mathrm{S}$ batteries used as traction batteries for electric and hybrid vehicles and are not concerned with stationary energy storage.

2 The Ad Hoc Electric Vehicle Battery Readiness Working Group consists of leading scientists and program managers from govemment agencies, battery developers, automobile manufacturers, and the chemical processing industry.
} 


\section{Table of Contents}

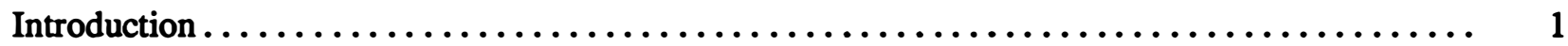

Potential EV Hazards $\ldots \ldots \ldots \ldots \ldots \ldots \ldots \ldots \ldots \ldots \ldots \ldots \ldots \ldots \ldots \ldots \ldots \ldots \ldots \ldots$

Electrical/Chemical/Thermal Hazards $\ldots \ldots \ldots \ldots \ldots \ldots \ldots \ldots \ldots \ldots \ldots \ldots \ldots . \ldots \ldots$

Mechanical and Operational Hazards ......................... 4

Standards, Regulations, and Guidelines $\ldots \ldots \ldots \ldots \ldots \ldots \ldots \ldots \ldots \ldots \ldots \ldots \ldots \ldots$

Existing Federal Motor Vehicle Safety Standards $\ldots \ldots \ldots \ldots \ldots \ldots \ldots \ldots \ldots \ldots$

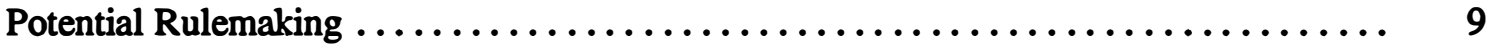

Electrical/Chemical/Thermal Hazards .................... 9

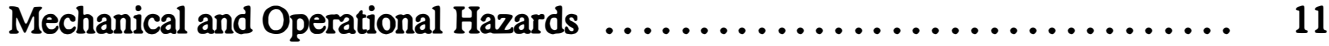

Conclusions and Recommendations $\ldots \ldots \ldots \ldots \ldots \ldots \ldots \ldots \ldots \ldots \ldots \ldots \ldots \ldots \ldots \ldots$

Adequacy of Regulations in Addressing Hazards $\ldots \ldots \ldots \ldots \ldots \ldots \ldots \ldots \ldots \ldots$

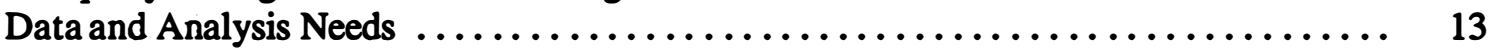

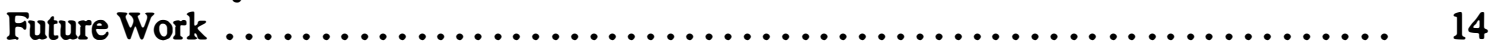

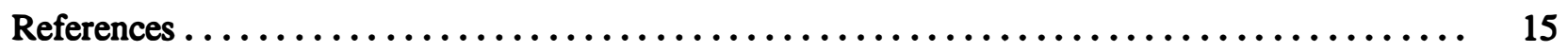

Appendix A Existing Federal Motor Vehicle Safety Standards $\ldots \ldots \ldots \ldots \ldots \ldots \ldots \ldots \ldots$ A-1

Appendix B Advanced Notice of Proposed Rulemaking for Electric Vehicles ........... B-1

Appendix C Industry Standards and Recommended Practices Potentially Applicable to EVs .... C-1 
TP-4952

\section{List of Tables}

Table 1 - Potential Electric Vehicle Hazards and Regulations $\ldots \ldots \ldots \ldots \ldots \ldots \ldots \ldots$

\section{List of Acronyms}

\begin{tabular}{|c|c|}
\hline ANPRM & Advanced Notice of Proposed Rulemaking \\
\hline DOE/EHP & $\begin{array}{l}\text { Electric and Hybrid Propulsion Division of the Office of Transportation Technologies } \\
\text { in the U.S. Department of Energy }\end{array}$ \\
\hline EV & Electric Vehicle \\
\hline FMVSS & Federal Motor Vehicle Safety Standard \\
\hline ICEV & Internal Combustion Engine Vehicle \\
\hline $\mathrm{Na} / \mathrm{S}$ & Sodium-sulfur \\
\hline NHTSA & National Highway Traffic Safety Administration, U.S. Department of Transportation \\
\hline RD\&D & Research, Development, and Demonstration \\
\hline Norking Group & Ad Hoc Electric Vehicle Battery Readiness Working Group \\
\hline
\end{tabular}




\section{Introduction}

The issue of vehicle safety may be the single most important environmental, health, and safety concern for electric vehicles (EVs) from the standpoint of consumer acceptance. According to a Business Week/Harris Poll, 99\% of those surveyed rated safety as "very important" or "somewhat important" when deciding which car to buy [3]. Since the mid-1970s, when the development of EVs began to gain momentum, there have been a number of assessments of the safety concerns presented by EV technology. In 1978, for example, the National Highway Traffic Safety Administration (NHTSA) published a report on the applicability of the existing Federal Motor Vehicle Safety Standards (FMVSS) to EVs, pointing out areas where EVs may have difficulty in meeting the FMVSS as well as safety hazards not addressed by the existing standards [4]. In 1982, the U.S. Department of Energy (DOE) commissioned the Aerospace Corporation to conduct a study on potential safety hazards of electric and hybrid vehicles [5]. In addition to presenting information similar to that in the NHTSA report, the Aerospace study also reviewed the applicability of standards promulgated by other organizations concerned with automobile safety, electrical hazards, and fire prevention.

Since that time, there have been other, but less complete, assessments of EV hazards and safety standards. The evolution of novel technologies and design options has presented new safety concerns as well as rendered obsolete some of the hazards previously identified. This paper revisits the issue of in-vehicle safety within the context of the developments of the last decade and (1) identifies the unique hazards associated with EV use; (2) describes the existing standards, regulations, and guidelines that are or could be applicable to these hazards; and (3) discusses the adequacy of the existing requirements in addressing the saf ety concerns of EVs. Although the primary focus of this discussion is EVs powered by sodium-sulfur ( $\mathrm{Na} / \mathrm{S})$ batteries, many of the hazards described here are generic to EVs and can be thought of as applicable to a wide range of battery types and designs. Those items of particular importance for $\mathrm{Na} / \mathrm{S}$ use are specifically identified throughout the text.

\section{Potential EV Hazards}

Electric vehicles present several unique hazards that are not experienced or do not occur to the same degree in conventional internal combustion engine vehicles (ICEVs). The reverse is certainly also true, because ICEVs are associated with particular environmental, health, and safety concerns not relevant to EVs (such as the use of large quantities of combustible fuels, oils, and coolants). In addition, conventional vehicles have benefitted from decades of development, whereas EVs are still a relatively new technology from a development standpoint.

Many of the safety concerns unique to EVs are derived from the high voltages involved in the energy storage and electrical drive systems of the vehicle. In addition, there are a number of mechanical hazards inherent in transportation vehicles that are exacerbated by the use of an electric propulsion system, both in conversions of conventional vehicles and in ground-up EV designs. Finally, the toxicity of the battery materials themselves presents particular problems for in-vehicle safety. The following sections describe the significant hazards unique to EVs (with particular emphasis on sodium-sulfur battery driven vehicles), mitigation 
techniques that are or could be built into the vehicle design, ${ }^{3}$ and the results of limited testing in this area. Even though a more comprehensive list of hazards could be discussed, ${ }^{4}$ the following is limited to those concerns that are deemed most significant for EV development from the point of view of both regulatory compliance and public acceptance. Table 1 lists the hazards discussed below, along with the applicable standards, regulations, or guidelines.

\section{Electrical/Chemical/Thermal Hazards}

The typical $\mathrm{Na} / \mathrm{S}$ battery for traction applications operates at between 200 and $300 \mathrm{~V}$, depending on the specific design [5,7]. In contrast with the typical $12-\mathrm{V}$ battery found in an ICEV, this poses a potentially lethal shock hazard - particularly during charging, maintenance, and in the event of a severe collision. Preventive measures might include electrically isolating the batteries and motor from the conductive components of the vehicle (e.g., the chassis), installing tamper-proof covers on the batteries to limit exposure during nonskilled maintenance, providing a mechanism for disabling the drive power circuitry during routine maintenance, and ensuring that insulating and protective material surrounds high-voltage components.

A related electrochemical hazard is that of a fire resulting from short-circuiting, overheating, or cell rupture. Short-circuiting could be caused by a poor connection during charging or operation as well as the failure of connectors or damage to the battery pack during collision. Overheating might result from overcharging, a failure of the thermal management system, or cell failure. An overvoltage supplied to a cell during charging could lead to fracturing of the ceramic electrolyte, allowing the sodium and sulfur to mix directly and generate large exotherms. ${ }^{5}$ Such a large heat release within a cell may cause a rupture of the cell walls and extend the damage to adjacent cells, having the potential for extensive damage from failure propagation. Failure tests conducted by one major Na/S battery manufacturer, Chloride Silent Power Limited (CSPL), demonstrate that through proper safety design, this problem can be avoided [8].

Besides overcharging, excessive heating may result from failure of the thermal management system. The thermal management system of a battery is designed to provide initial heatup of the battery, control waste heat buildup, and insulate the system. A typical Na/S battery operates between $300^{\circ}$ and $400^{\circ} \mathrm{C}$ [5] and is maintained at that temperature because of heat generated by internal resistance losses during normal operation; however, the heat inside the battery will rise with the rate of discharge, and excessive temperatures, which could cause cell failure and further heating, might result if the cooling system does not respond adequately.

${ }^{3}$ Mitigation measures specifically related to cell and battery safety are discussed separately in reference 6 and are not included here.

${ }^{4}$ See, for example, reference 5 .

s This section concentrates on the causes and consequences of certain cell and battery safety hazards. For a more thorough description of the mechanisms involved and the available mitigation measures, see reference 6. 
Table 1. Potential EV Hazards and Regulations

\begin{tabular}{|c|c|c|c|}
\hline $\begin{array}{l}\text { Potential } \\
\text { Hazard }\end{array}$ & $\begin{array}{l}\text { Existing or Potential } \\
\text { Regulation }^{\mathrm{b}}\end{array}$ & $\begin{array}{l}\text { Respc } \\
\text { DOE/EHP }\end{array}$ & $\begin{array}{l}\text { onsec }^{\text {Ad Hoc }} \\
\text { Ad }\end{array}$ \\
\hline \multicolumn{4}{|l|}{ Electric Shock } \\
\hline Recharging & ANPRM 1(a) - standardization & no & no \\
\hline Maintenance & ANPRM 1(b) - main drive power disable & no & no \\
\hline \multirow[t]{2}{*}{ Collision } & ANPRM 3(a) - electrical isolation & no & no \\
\hline & ANPRM 3(f) - automatic disconnect & modification & w/modificatior \\
\hline \multirow[t]{2}{*}{ Electric Malfunction } & ANPRM 2(h) - warning indicator & no & no \\
\hline & ANPRM 2(d) - positive disconnect & no & no \\
\hline \multicolumn{4}{|l|}{ Fuel System Integrity } \\
\hline Combustion fuels & FMVSS No. 301 - fuel system integrity & yes & -- \\
\hline Electrolyte spillage & ANPRM 3(d) - maximum discharge & ?d & ? \\
\hline \multicolumn{4}{|l|}{ Thermal Hazards } \\
\hline Flame propagation & ANPRM 2(b) - flame barriers & no & no \\
\hline Explosive gases & ANPRM 2(c) - battery vents & no & no \\
\hline High temperature & ANPRM 3(e) - exposure limitations & no & no \\
\hline Performance & ANPRM 2(e) - minimum performance & no & no \\
\hline \multirow[t]{2}{*}{ Reverse Operation } & ANPRM 2(f) - maximum speed & no & no \\
\hline & ANPRM 2(a) - audible waming device & no & no \\
\hline \multirow[t]{2}{*}{ Braking } & FMVSS No. 102 - transmission braking (multispeed) & d) yes & -- \\
\hline & ANPRM 2(g) - transmission braking (single speed) & no & yes \\
\hline Battery Restraint & ANPRM 3(b,c) - battery restraint & $?$ & no \\
\hline \multirow[t]{2}{*}{ Crashworthiness } & FMVSS No. 204 - steering control rear displacement & nt yes & -- \\
\hline & FMVSS No. 208 - occupant crash protection & yes & -- \\
\hline
\end{tabular}

- See text for discussion.

${ }^{b}$ Numbers and letters refer to specific items in the ANPRM. See Appendix B for full documentation.

c Response of DOE/EHP [10] and the Ad Hoc Electric Vehicle Battery Readiness Working Group [11], indicating whether or not they support regulation for each item discussed in the ANPRM.

'A "?" indicates that a definite yes or no answer is not appropriate. See text for further discussion. 
In addition to those safety concerns that result from the electrical propulsion system of electric vehicles (EVs), the electrolyte materials ${ }^{6}$ used in advanced batteries pose unique chemical hazards. Both the sodium and the sulfur of a $\mathrm{Na} / \mathrm{S}$ battery are reactive elements, and a collision resulting in their release to the environment inside or outside the vehicle could have several severe effects. Through a variety of potential reactions, the molten sodium and sulfur released from a battery are capable of generating large quantities of heat, explosive and toxic gases, and other caustic chemical compounds.? Preventative measures are specific to cell and battery design and are discussed at length in reference 6.

\section{Mechanical and Operational Hazards}

Although the majority of components in an EV are identical to those found in a conventional vehicle, the replacement of the internal combustion engine with an electric propulsion system effects a number of important mechanical and operational changes. The performance of EVs is a hotly debated topic that is expected to be major factor in whether EVs are accepted on a widespread basis. In general, differences in performance (if they do exist) do not pose significant safety hazards, although EVs that are not capable of accelerating at the same rate as ICEVs might impose particular operational safety problems (e.g., in merging onto a highway). Vehicles operating on Na/S batteries have demonstrated maximum speeds of $100-129 \mathrm{~km} / \mathrm{h}$ (62-80 $\mathrm{mph})$ and acceleration from $0-80 \mathrm{~km} / \mathrm{h}(0-50 \mathrm{mph})$ in $14-18$ seconds $[12,13]$. These performance characteristics do not equal those of a sport ICEV, but they are within the bounds currently demonstrated by conventional vehicles.

Because the weight of the batteries required to provide EVs with a reasonable driving range is large (360 $\mathrm{kg}$, or $800 \mathrm{lb}$, in Ford's new Ecostar van, for example [7]), the conversion of an ICEV to an EV can add substantial mass to the vehicle. The added weight may limit the maneuverability of the vehicle as well as increase its inertial force during sudden stops and collisions. In addition, the movement of the battery unit could pose a significant hazard in the event of a collision.

On the other hand, it is expected that future EVs will be designed to decrease the weight of the nonpropulsion components in an effort to increase range, and it is possible that the lighter components used in these vehicles will have a lower crash energy management capacity. ${ }^{8}$ Very little test data are available, primarily because of a lack of extensive testing and proprietary concerns that limit the dissemination of information. In the early eighties, DOE sponsored the development of two electric vehicles, the ETV-1 and ETV-2, and

${ }^{6}$ Strictly speaking, the term electrolyte refers solely to the material that transfers electrons - in this case the beta"alumina. In an effort to remain consistent with the general literature $([9,10,11])$, it is used here more broadly to refer to all of the battery materials (sodium, sulfur, beta alumina) involved in the electrochemical reactions that generate electricity. 6.

'For a more complete description of the chemical hazards of sodium, sulfur, and related compounds, see reference

${ }^{8}$ Crash energy management capacity is the ability of a vehicle to absorb and direct the energy of a collision. A higher capacity, which is not necessarily related to vehicle weight, results in less deformation of the vehicle and greater protection of the occupants. 
conducted crash testing on both vehicles. The ETV-1 design included some lighter-weight components, while the ETV-2 was constructed of a fiber-reinforced plastic for a maximum strength-to-weight ratio. The crashworthiness of the ETV-1 vehicle was demonstrated on a mule vehicle, derived from a 1977 Chrysler Omni-Horizon, and the appropriate safety standards were met. Testing of the ETV-2 design was performed on a half-scale model, and again the design was shown to possess adequate crash management capabilities [5].

In addition to lighter-weight components, future EVs are expected to incorporate regenerative braking as a means of extending range. In such a system, the braking energy is converted into electricity by running the motor as a generator to partially recharge the batteries. This extends the charge on the batteries and has an effect similar to ransmission braking experienced in an ICEV. However, whereas transmission braking in conventional vehicles is most effective in the lower gears (because of the gearing ratio), regenerative braking in EVs is generally thought of as useful only at speeds above $15-20 \mathrm{mph}$ [5]. ${ }^{9}$ At higher speeds, both types of vehicles will experience retarding effects because of rolling resistance and air resistance, but these forces diminish at lower velocities. It is therefore at lower speeds that a braking effect (such as transmission braking) is particularly helpful in reducing the load on the normal service brakes. Although adequate test data have not been published to provide conclusive evidence, an EV with regenerative braking may not be capable of providing such aid. This can increase the wear on the service brakes and may cause EVs to operate differently than what users have come to expect in conventional vehicles.

In both an ICEV and an EV, the windshield wipers, lights, and indicators are all electrically driven. Should the propulsion system fail in an ICEV, these will continue to operate. In most EV designs, these peripherals are operated under separate electrical circuits; however, there have been some discussions regarding eliminating the $12-\mathrm{V}$ auxiliary battery and operating accessories off of the propulsion battery using a converter. Such systems, without adequate backup mechanisms, could raise safety concerns in the event of an interruption of propulsive power.

A final concern relating to the operation of EVs is driving in reverse. Since for many of these vehicles, operation in reverse will be achieved by simply reversing the direction of the motor, an EV may be capable of going backwards at high velocities. This could present a safety hazard, and some have suggested a limitation on the maximum reverse speed. In addition, since EVs operate very quietly, there is little audible warning of their backing up (although some have argued that many ICEVs are also very quiet at idle and low speeds, and thus the concern may not be unique to EVs). One option would be to require a device to sound when operating in reverse. Both of these features have been successfully designed into EVs in the past, such as the Lucas EVs operated in the United Kingdom [14].

\section{Standards, Regulations, and Guidelines}

The National Highway Traffic Safety Administration (NHTSA) under the U.S. Department of Transportation is responsible for safety regulations of motor vehicles. Its role is to monitor adherence to the Federal Motor

\footnotetext{
9 Recent information from the automobile manufacturers indicates that the lower limit for regenerative braking effects may be approaching $5 \mathrm{mph}$ or lower. However, because of the paucity of published data from the industry, this report continues to assume that the lower limit is $15-20 \mathrm{mph}$ as has been determined in the past. Continued vehicle testing and demonstration programs may help to revise this estimate.
} 
Vehicle Safety Standards (FMVSS), conduct safety investigations, and propose new standards when necessary. The FMVSS, published in 49 CFR Part 571, set minimum standards for motor vehicle safety performance and are intended to protect the public against unreasonable risk of crash occurrence and crashes resulting in death or serious injury. They are organized into three sections: the 100 series on crash avoidance to reduce the likelihood of a crash by addressing vehicle components such as brake systems, lighting, tires, controls, and displays; the 200 series on crashworthiness standards and testing procedures to reduce the risks of crash fatalities or serious injuries by addressing such items as vehicle structure, occupant crash protection, and occupant restraints; and the 300 series on fire prevention and the reduction of post-crash hazards by addressing such items as fuel spillage and flammability of interior materials. In addition, certain FMVSS in the 200 and 300 series (FMVSS Nos. 204, 208, 212, 219, and 301) must meet the 30-mph barrier crash testing standards..$^{10}$

Certification of compliance with the FMVSS is provided by the manufacturer, who must be able to represent to NHTSA that "due care" was used in designing and certifying the vehicles [15]. Vehicles sold must have a certification label verifying that the vehicle meets all FMVSS or listing the exemptions that the vehicle may have. NHTSA conducts random testing of vehicles already on the market to monitor the auto manufacturers.

NHTSA has recently issued an Advanced Notice of Proposed Rulemaking (ANPRM) regarding new and amended FMVSS that would apply to electric vehicles. The purpose of the notice is to solicit comments on the issues identified in the ANPRM and opinions as to whether NHTSA should be considering rulemaking to address these issues. The U.S. Department of Energy's Electric and Hybrid Propulsion Division and the Ad Hoc Electric Vehicle Battery Readiness Working Group have made formal responses to the ANPRM $[10,11]$, and their comments are described below." In addition, the major safety issues, the applicable standards, and the responses of these two interested parties to the ANPRM are summarized in Table 1. Following the ANPRM, NHTSA will release a Notice of Proposed Rulemaking (NPRM) that will actually propose specific regulations for public comment before drafting final standards.

The U.S. Department of Energy has been involved with electric and hybrid vehicle development since 1976, when Congress passed the Electric and Hybrid Vehicle Research, Development, and Demonstration Act (Public Law 94-413) [9]. Currently, these activities are under the auspices of the Electric and Hybrid Propulsion (DOE/EHP) Program within the Office of Conservation and Renewable Energy. A more recent participant in EV development activities is the Ad Hoc Electric Vehicle Battery Readiness Working Group, which consists of leading scientists and program managers from government agencies (including DOE/EHP), battery developers, automobile manufacturers, and the chemical processing industry. The comments of both groups are included below with the discussion of the ANPRM; however, only DOE/EHP responded to the proposed amendments to the existing FMVSS.

D A complete list of current FMVSS is found in Appendix A.

"Forty-four other organizations have made formal responses to the ANPRM; however, this paper limits itself to the responses of the Department of Energy and the Ad Hoc Electric Vehicle Battery Readiness Working Group, which together offer a broad-based industry-government opinion. 
Besides the existing or proposed FMVSS, there are a number of standards promulgated by, among others, the Society of Automotive Engineers (SAE), the National Electrical Manufacturers Association (NEMA), the National Fire Protection Association (NFPA), the Institute of Electrical and Electronics Engineers (IEEE), and the Military Specifications (MIL) that may apply to EV components. Such industry standards and recommended practices may provide guidance for battery developers and EV manufacturers in addressing safety concerns. In most cases, they do not specifically apply to those hazards identified here as unique to EVs, but their use could help to mitigate safety concems presented by the widespread use of EVs. An annotated list of these standards is found in Appendix C.

\section{Existing Federal Motor Vehicle Safety Standards}

NHTSA has determined that "EVs should comply with the intent or purpose of all existing standards" [9]. The agency recognizes, however, the need to modify some of the existing regulations that are oriented toward ICEV s or that do not adequately respond to the unique hazards associated with EVs. The following discusses only those standards that may require modification and only the portion of each standard that is subject to change, as identified by NHTSA's ANPRM [9].12

\section{FMVSS No. 102: Transmission Shift Level Sequence, Starter Interlock, and Transmission Braking Effect}

Under this standard, transmission braking is required for automatic, multispeed transmission vehicles at speeds below $25 \mathrm{mph}$. In a manual transmission vehicle, this action is achieved by manually shifting down to a lower gear, causing the engine to slow the forward movement; however, an automatic transmission does not allow the operator to control this action to such an extent (many multispeed automatics do permit some degree of manual down-shifting). The intent of the regulation is to assist the service braking system at these speeds and to ensure that vehicle operation is consistent with what operators have come to expect [15,16]. The regulation does not, however, quantify the level of supplementary braking to be supplied by the transmission. In addition, it only applies to vehicles with automatic, multispeed transmissions.

Compliance with the intent of this standard would require EVs with multispeed automatic transmissions to demonstrate that regenerative braking (the EV equivalent of transmission braking) is effective at speeds below $25 \mathrm{mph}$. As noted earlier, such braking is most effective in the range above $15-20 \mathrm{mph}$; however, given that there is no quantification of the rate of deceleration required of the transmission braking effect, it may be possible that regenerative braking will be sufficient. The position of DOE/EHP is that EVs with automatic multispeed transmissions should be required to comply with this standard. On the other hand, it is expected that the majority of commercial EVs will be propelled by a single-speed transmission [10], in which case FMVSS No. 102 does not apply.

\section{FMVSS No. 103: Windshield Defrosting and Defogging Systems}

This standard specifies requirements for windshield defrosting and defogging, which must be achieved within a certain time period after allowing for engine warm-up. Defrosting and defogging in an EV can be achieved by an on-board combustion heater or through routing waste heat generated by the motor, controller, or

The full documentation of the ANPRM is included in Appendix B. 
batteries. In either case, the statement regarding engine warm-up is irrelevant to EVs, although some time for the combustion heater or propulsion system to begin generating heat may be required. It is the position of DOE/EHP that, with proper rewording, compliance with this standard should be mandatory for EVs.

\section{FMVSS No. 105: Hydraulic Brake Systems}

This standard applies to both hydraulic service brakes and parking brake systems and includes testing procedures that require that an EV be placed in neutral. This may be difficult for vehicles with direct drive and/or regenerative braking, and the standard may need to be modified for EVs incapable of reaching "neutral" [9].

FMVSS No. 204: Steering Control Rearward Displacement and FMVSS No. 208: Occupant Crash Protection

Both of these standards specify minimum levels of crashworthiness during a 30-mph rigid barrier collision. As noted above, EVs converted from ICEVs might experience a significant weight gain, which may affect their crashworthiness. Because of the increased momentum experienced by a heavier mass, overall deformation may be more significant, thereby making compliance with FMVSS No. 204, which specifies a maximum rearward displacement of the steering column during a crash, more difficult. On the other hand, vehicles designed exclusively for use with electric propulsion systems may be lighter in order to extend vehicle range. For these, the crash energy management capability of the vehicle may be insufficient to meet the standards of FMVSS No. 208 requiring adequate occupant protection. In either case, the standards will provide a temporary exemption for up to 2500 vehicles per year for the "development and field evaluation of low-emission motor vehicles" [9]. NHTSA is discussing the possibility of increasing the number of vehicles that may be produced in a given year as well as the length of the temporary exemption [9]. The response of DOE/EHP is that the exemptions should not be extended, sinceit is their contention that "electric vehicles can comply with the current standards using existing technology" [10].

\section{FMVSS No. 301: Fuel System Integrity}

This standard specifies requirements for the integrity of fuel systems to reduce the chance of fires resulting from fuel spillage during and after vehicle crashes. Maximum fuel spillage is indicated for rollover, frontal barrier, and rear moving barrier tests. For ICEVs, fuel spillage is limited to $1 \mathrm{oz}$. from impact until the motion of the vehicle has ceased and $5 \mathrm{oz}$. in the 5-minute period following the cessation of motion [16]. EVs that use combustion heaters are expected to be required to meet this standard for the on-board combustible fuels associated with these systems; however, there is uncertainty conceming how the electrolyte battery materials used in EVs should be treated. Preliminary attempts have been made to relate the existing fuel system integrity standard to electrolytic materials on an energy-equivalence basis [17]. Another option might be to perform a risk analysis to determine appropriate maximum electrolyte spillage rates. DOE/EHP recommends that a new rulemaking be considered for exposure to battery materials and that FMVSS No. 301 be maintained for application to combustible fuels used in heating systems. 


\section{Potential Rulemaking}

Because of the unique hazards associated with EV operation and maintenance, NHTSA is considering the need for new standards for application to EVs, and these issues are discussed in this section. The full documentation of the ANPRM is found in Appendix B, and the numbers in parentheses in the following text correspond to specific items found in the ANPRM. The responses of the DOE/EHP [10] are included, as before, as well as those of the Ad Hoc Electric Vehicle Battery Readiness Working Group (hereafter referred to as the Working Group) [11]. The responses and potential rules are summarized in Table 1 at the end of this section.

\section{Electrical/Chemical/Thermal Hazards}

\section{Electric Shock - Recharging}

NHTSA is considering the need for rulemaking that would "standardize cables, connectors, receptacles, transformers, and procedures involved in the recharging of the traction and propulsion battery systems" (1a) ${ }^{13}$ [9]. Such a rule would address the shock and fire hazards associated with charging. The position of both DOE/EHP and the Working Group is that there are a number of standards and regulations that already apply to these components. Moreover, the Electric Power Research Institute, in conjunction with electric utilities, battery designers, and automobile manufacturers, is currently involved in an effort to clarify the power source/vehicle interface, including the standardization of recharging activities.

\section{Electric Shock - Maintenance}

NHTSA is also considering a rule that would standardize a method for disabling the main drive power during maintenance (1b). Such a provision would address those electrical shock and fire hazards associated with maintaining the vehicle, either by trained repair personnel or individual vehicle operators. The DOE/EHP and Working Group response is that such a measure may not be necessary since adequate protection may be achievable through proper design of covers and insulators. The Working Group additionally notes that such a regulation would be more restrictive than those currently applied to ICEVs.

\section{Electric Shock - Collision}

The major electrical hazard associated with collisions is the potential for shock from the exposure to high voltages because of damage to the propulsion system. NHTSA is considering two different standards to address this issue. First, it suggests a regulation to require that the electric propulsion circuit is electrically isolated from the remainder of the vehicle (3a). According to DOE/EHP, electrical isolation is the current industry practice, but it opposes regulation since a standard will be difficult to quantify and testing of compliance will not necessarily ensure isolation under all conditions. The Working Group recognizes the importance of this practice as well but opposes rulemaking until there is a determined need for regulation.

NHTSA has also suggested that a standard may be necessary to require the propulsion battery circuit to be automatically disconnected in the event of a severe collision (3f). This would also reduce shock and fire

${ }^{B}$ Refers to specific items in the ANPRM. See Appendix B for full documentation. 
hazards as well as ensure that power to the drive wheels is disconnected in the event of a severe collision. Both DOE/EHP and the Working Group contend that, while such effects are desirable, the specific mechanism for achieving this should not be determined by NHTSA. Instead, they propose that any standard be performance oriented such that the regulation specifies a criterion to be met by EVs, not the method for achieving it.

\section{Electrical Malfunction}

NHTSA is considering a rule requiring EVs to have an indicator to wam the driver of an electrical malfunction in the propulsion system (2h). Such a device would be important in advising the operator of problems; however, it is the position of both DOE/EHP and the Working Group that "such devices will evolve with experience [as they have for conventional vehicles] and need not be regulated into existence" [11].

In addition, NHTSA is examining the need for a standard to require a positive disconnect device to electrically decouple the propulsion system in the event of short-circuiting or other battery malfunction (2d). Such a device would be located such that is could be operated from the driver's normal location. DOE/EHP and the Working Group have both responded against such a rule, stating that such a device could be activated by a nondriver (e.g., children); it makes EVs look inherently unsafe; and other disconnection methods might be used, such as the vehicle key switch.

\section{Electrolyte Spillage}

As noted above, a significant chemical hazard exists in the event that electrolyte from the batteries is spilled during or following a collision. Strictly speaking, this is not regulated under the auspices of FMVSS No. 301 (fuel system integrity), which applies to combustible fuels. NHTSA is considering rules to address this issue (3d). No similar standard exists for the starting, lighting, and ignition batteries found in ICEVs; however, the use of reactive materials in advanced batteries, such as sodium and sulfur, may make a specific regulation prudent. Little test data are available, and no risk analyses have treated this issue thoroughly. As DOE/EHP and the Working Group point out, because of the wide variety of chemical hazards associated with different materials, it is clear that different types of batteries will require separate maximum spillage rates if rulemaking is imposed and specific quantities are declared [10,11].

\section{Thermal Hazards}

NHTSA is considering the need for regulations that would require flame barriers (2b) and battery vents (2c) to reduce therisk of explosion resulting from flame propagation or the accumulation of explosive gases. The responses of both DOE/EHP and the Working Group indicate that some battery types, such as sodium-sulfur, do not generate explosive gases. In addition, they feel that this is an issue for battery designers and should not be subject to specific rules. A number of battery safety issues, such as overcharging, thermal management, and cell failure, are described in detail in reference 6 and are therefore not included in this discussion of in-vehicle safety.

NHTSA has also inquired whether a rule limiting exposure to high-temperature battery components should be promulgated (3c). Again, both DOE/EHP and the Working Group oppose such rulemaking, and they cite the fact that "regulation has not been found necessary to limit exposure to the high temperatures of 
conventional vehicle components (exhaust pipes, catalytic converters, engine surface temperatures) which exceed the temperatures anticipated on EVs" [11]. In addition, high-temperature batteries, such as sodium-sulfur, will already require insulation for proper thermal management [10].

\section{Mechanical and Operational Hazards}

\section{Performance}

NHTSA is considering rulemaking to set a minimum level of acceleration and speed performance for EVs to prevent inadequate performance in an environment that includes ICEVs (2e). Both DOE/EHP and the Working Group note that no standard currently exists for conventional vehicles and that the marketplace has established the level of acceptable performance. In addition, they mention that EVs are "easily" capable of attaining the same top speeds and acceleration rates as conventional vehicles.

\section{Reverse Operation}

NHTSA is examining the necessity of standards relating to the reverse operation of EVs. As described above, EVs with single speed drives are capable of operating in reverse at the same speeds attained in the forward direction. In an effort to ensure safe operation, NHTSA is considering a maximum speed for reverse operation of those vehicles (2f). Both the Working Group and DOE/EHP note that such a requirement does not exist for conventional vehicles and has not been found to be necessary. DOE/EHP also notes that conventional vehicles are also capable of operating in reverse at speeds "in excess of what is considered safe" [10].

A second issue related to reverse operation is the low noise levels associated with EVs and the potential hazards to nearby pedestrians and traffic. NHTSA has requested comment on whether a requirement to provide an audible signal while an EV is backing up is necessary (2a). Again, the response of DOE/EHP and the Working Group is that such a standard places undue constraints on EVs since conventional light-duty vehicles are not subject to such a rule, even though their reverseoperation may not be audible above ambient noise levels in many situations.

\section{Braking}

FMVSS No. 102, which includes a provision for transmission braking below $25 \mathrm{mph}$, applies only to multispeed automatic transmissions. NHTSA is considering rulemaking that would require single-speed EVs to also have the equivalent of a transmission braking effect $(2 \mathrm{~g})$. It has also discussed the possibility of setting a specific deceleration rate, something that does not exist for FMVSS No. 102 at present. DOE/EHP's position is that such a requirement places undue restrictions on EVs and may therefore constrain technological development. In addition, it opposes a specific deceleration rate standard as more restrictive than existing regulations under FMVSS No. 102 [10]. The Working Group differs in its response, indicating that a braking effect requirement for EVs would be appropriate and consistent with FMVSS No. 102. It also describes that, without such a standard, EVs might operate differently than what users have come to expect in conventional vehicles [11]. 


\section{Battery Restraint}

FMVSS Nos. 204, 208, 212, 219, and 301, ${ }^{14}$ which require a 30-mph barrier crash test, are designed to protect the occupants of a vehicle in the event of a collision. Concerns were described earlier regarding the ability of EVs to comply with two of these standards, Nos. 204 (steering control rearward displacement) and 208 (occupant crash protection) because of differences in vehicle mass or crash energy management capacity; however, the potential for the movement of the battery pack poses an additional hazard because of the large mass of the batteries. NHTSA is considering whether the existing regulations governing collisions (specifically, Nos. 208 and 301) are sufficient to address this hazard or if new standards should be drawn up to specifically require batteries to remain inside the vehicle but outside the occupant compartment in a 30mph barrier crash test (3b, 3c). DOE/EHP and the Working Group feel that it is important to comply with the intent of FMVSS No. 208 and that FMVSS No. 301 (fuel system integrity) should apply only to combustible liquids, as discussed above. Further rulemaking regarding battery materials constraint may not be necessary if adherence to FMVSS No. 208 and FMVSS No. 301 (for combustible liquids only) is required and a new regulation regarding electrolyte spillage is established [11]. If NHTSA does promulgate a separate rule for battery restraint, DOE/EHP indicates that compliance with the 30 -mph barrier test is technically feasible [10].

* See Appendix A for a complete list of current FMVSS. 
TP-4952

\section{Conclusions and Recommendations}

\section{Adequacy of Regulations in Addressing Hazards}

One of the purposes of the rulemaking process is to anticipate as many potential hazards as possible [18]. Table 1 lists the major in-vehicle safety issues as identified here as well as the existing or potential standards that are applicable. Even though these hazards appear to have been adequately addressed in the ANPRM and/or the comments on the ANPRM submitted by DOE/EHP and the Working Group, it can also be expected that new concerns may arise as EVs begin large-scale penetration of the vehicle market. In addition, some of the potential standards proposed in the ANPRM apply to safety hazards that may never materialize.

For the most part, the existing FMVSS for conventional vehicles were generated in response to identified hazards based on actual vehicle operating data. This will not be the case for EVs, since there is little information available with respect to operating or testing EVs. The reaction of both DOE/EHP and the Working Group to the regulatory process is best summarized by the following four statements [11]:

1. Regulations placed on electric vehicles should not be more restrictive than the regulations which currently exist for conventional vehicles.

2. Regulations should be described in terms of performance criteria instead of design specifications.

3. Regulations should only be promulgated in response to a demonstrated need, and not made in anticipation of safety problems which may never materialize, and

4. Electric vehicles do not require changes in the exemption provisions of the Vehicle Safety Act.

\section{Data and Analysis Needs}

If nothing else, the debate over regulations governing in-vehicle safety highlights the need for further information regarding hazards and the risks imposed by such hazards. Areas that require further definition include acceptable levels of electrolyte spillage, the effectiveness of regenerative braking at speeds below 25 $\mathrm{mph}$, the crashworthiness of EVs either converted from conventional vehicles or built from the ground up using lighter weight materials, and the effectiveness of shock and fire prevention devices.

In the absence of actual operating data, testing is a useful means of determining more information about many of these hazards. By simulating crash situations, testing can identify whether particular safety concerns have been adequately addressed in vehicle designs. In addition, compliance with particular performance criteria can be demonstrated through vehicle testing. As demonstrated in this report, there is little available information regarding EV safety testing, both because extensive tests have not been performed and because much of this information is considered proprietary. In either case, it will become important for EV manufacturers to demonstrate that their vehicles do indeed operate safely in order to successfully penetrate the vehicle market.

Besides data developed from testing, analytical methods such as risk analysis can be used to identify and quantify the danger posed by particular hazards. This four-step process, as outlined by the Council on Environmental Quality [2], includes (1) hazard identification, (2) risk assessment (an estimation of the 
severity and likelihood of a particular hazard), (3) determination of the significance of a risk, and (4) risk communication to the affected populations. The application of such a procedure to the hazards posed by electrolyte spillage, for example, would be one method of establishing a standard for the maximum release rate allowable in a collision, similar to those levels set for conventional vehicles by FMVSS 301 (Fuel System Integrity). In addition to regulatory support, risk analysis will both aid in the education of the public and help battery and vehicle designers to focus their attention on the most significant hazards.

\section{Future Work}

Near-term work in the area of in-vehicle safety should focus on developing more information regarding EV safety, particularly with respect to those unique hazards experienced by EVs. Specific activities in this vein might include (1) a more extensive testing and demonstration plan and (2) risk analyses to assess major safety concerns and put them into a meaningful format for discussion (e.g., by identifying and determining the significance of particular risks).

Beyond information development, there is also a need to assess the mechanisms involved in internalizing these hazards into society. For example, the links between specific risks or preventative measures and economic or social costs need to be illuminated. In addition, the relationship of safety, regulations, and liability is a topic that has not been adequately addressed but is one that may have far-reaching effects for EV consumers and manufacturers. Finally, the education of consumers is an area that will require further attention in order to facilitate the penetration of EVs into the vehicle marketplace. 


\section{References}

1. P.G. Patil, et al., "Shipping, Use, and Disposal/Recycle Considerations for Sodium/Beta Batteries in EV Applications," Proceedings of the Beta Battery Workshop, Chester, England, June 12-14, 1990.

2. J.J. Cohrssen and V.T. Covello, Risk Analysis: A Guide to Principles and Methods for Analyzing Health and Environmental Risks, Washington, DC: Council on Environmental Quality, 1989.

3. J.B. Treace, et al, "Can Detroit Hold its Lead in Safety?" Business Week, November 26, 1990, pp. 127128.

4. National Highway Traffic Safety Administration, Applicability of Federal Motor Vehicle Standords to Electric and Hybrid Vehicles, DOT-HS-802-611, 1978.

5. P.J. Brown and R.T. Hall, "Safety Considerations for Electric and Hybrid Vehicles," SAE Technical Paper Series 821164, Reprint from P-113 Twenty-Sixth Strapp Car Crash Conference, October 20-21, 1982.

6. J.M. Ohi, Environment, Health, and Safety Issues of Sodium-Sulfur Batteries for Electric and Hybrid Vehicles, Volume I: Cell and Battery Safety, National Renewable Energy Laboratory, NRELTP-2624678, September 1992.

7. R. Rowand, "Electric Vehicle Research Gives Boost to Plastics," Automotive News, April 13, 1992, p. 22.

8. F.M. Stackpool, "Cell Development - A Focus on Safety," Proceedings: DOE/EPRI Beta (Sodium/Sulfur) Battery Workshop VII, October 1988.

9. National Highway Traffic Safety Administration, "Advance Notice of Proposed Rulemaking, Federal Motor Vehicle Safety Standards, Electric Vehicles, Docket No. 91-49; Notice 1," December 1991.

10. U.S. Department of Energy/Electric and Hybrid Propulsion Division, "Comments on NHTSA Advance Notice of Proposed Rulemaking, Federal Motor Vehicle Safety Standards, Electric Vehicles, Docket No. 91-49; Notice 1," March 23, 1992.

11. Ad Hoc Electric Vehicle Battery Readiness ANPRM Sub-Working Group. "Revised Response to NHTSA Advance Notice of Proposed Rulemaking - GHC-14-92," March 9, 1992.

12. W. Fisher and T. Shiota, "State of Development of Sodium Sulphur Traction Batteries at ABB and Powerplex," Conference Paper EVS88-053. Ninth International Electric Vehicle Symposium. Toronto, Canada, November 1988.

13. Electric Vehicle Association of the Americas, Presentation Material. 
14. G.G. Harding, "Some Aspects of Electric Vehicle Safety," The Fifth International Electric Vehicle Symposium, Philadelphia, October 2-5, 1978.

15. R. Krauss, "Automotive Safety, Government Regulation and the Electric Vehicle," National Highway Traffic Safety Administration, undated.

16. Code of Federal Regulations, "Part 571: Federal Motor Vehicle Safety Standards," General Services Administrations. pp. 174-580, revised October 1, 1991.

17. F. Stodolosky, "Safety Considerations for Sodium-Sulfur Batteries for Electric Vehicles," Recent Advances in Electric Vehicle Technology. SAE-SP-793. Future Transportation Technology Conference and Exposition, Vancouver, Canada, 1989.

18. S. Daniel, National Highway Traffic Safety Administration, personal communication, June 1992. 


\title{
Appendix A. Existing Federal Motor Vehicle Safety Standards*
}

\author{
Standard No. Title \\ 101 \\ 102 \\ 103 \\ 104 \\ 105 \\ 106 \\ 107 \\ 108 \\ 109 \\ 110 \\ 111 \\ 112 \\ 113 \\ 114 \\ 115 \\ 116 \\ 117 \\ 118 \\ 119 \\ 120 \\ 121 \\ 122 \\ 123 \\ 124 \\ 125 \\ 126 \\ 129 \\ 131 \\ 201 \\ 202 \\ 203 \\ 204 \\ 205 \\ 206 \\ 207 \\ 208 \\ 209 \\ 210 \\ 211 \\ 212 \\ 213 \\ Controls and displays \\ Transmission shift lever sequence, starter interlock, and transmission braking effect \\ Windshield defrosting and defogging systems \\ Windshield wiping and washing systems \\ Hydraulic brake systems \\ Brake hoses \\ Reflecting surfaces \\ Lamps, reflective devices, and associated equipment \\ New pneumatic tires \\ Tire selection and rims \\ Rearview mirrors \\ Headlamp concealment devices \\ Hood latch system \\ Theft protection \\ Vehicle identification number - basic requirements \\ Motor vehicle brake fluids \\ Retreaded pneumatic tires \\ Power-operated window systems \\ New pneumatic tires for vehicles other than passenger cars \\ Tire selection and rims for motor vehicles other than passenger cars \\ Air brake systems \\ Motorcycle brake systems \\ Motorcycle controls and displays \\ Accelerator control systems \\ Waming devices \\ Truck-camper loading \\ New non-pneumatic tires for passenger cars \\ School bus pedestrian safety devices \\ Occupant protection in interior impact \\ Head restraints \\ Impact protection for the driver from the steering control system \\ Steering control rearward displacement \\ Glazing materials \\ Door locks and door retention components \\ Seating systems \\ Occupant crash protection \\ Seat belt assemblies \\ Seat belt assembly anchorages \\ Wheel nuts, wheel discs, and hub caps \\ Windshield mounting \\ Child restraint systems
}


Standard No. Title

214

215

216

217

218

219

220

221

222

301

302

Side impact protection

[reserved]

Roof crush resistance - passenger cars

Bus window retention and release

Motorcycle helmets

Windshield zone intrusion

School bus rollover protection

School bus body joint strength

School bus passenger seating and crash protection

Fuel system integrity

Flammability of interior materials

*Source: Code of Federal Regulations, "Part 571: Federal Motor Vehicle Safety Standards," General Services Administrations. pp. 174-580, revised October 1, 1991. 
Appendix B

Advanced Notice of Proposed Rulemaking for Electric Vehicles

B-1 
DEPARTMENT OF TRANSPORTATION

National Highway Traffic Safety Administration

49 CFR Part 571

[Docket No. 91-49; Notice 1]

RIN 2127-AE29

Fedéral Motor Vehicle Safety Standards, Electric Vehicles

Agency: National Highway Traffic Safety Administration (NHTSA), DOT.

Action: Advance notice of proposed rulemaking.

SUMMARY: This advance notice of proposed rulemaking requests comments on potential safety-related issues associated with the use of electric vehicles and solicits ideas on whether NHTSA should, and if so how it might, address those problems through possible new and amended Federal Motor Vehicle Safety Standards. The purpose of this notice is to solicit comments to help NHTSA determine what existing Standards may need modification to meet the needs associated with the introduction of significant numbers of electric vehicles and what new Standards may have to be written specifically for electric vehicles.

DATES: The comment closing date for the advance notice is March 27, 1992.

ADDRESSES: Comments should refer to the docket number and notice number shown above and be submitted in writing to: Docket Section, National Highway Traffic Safety Administration, room 5109, 400 Seventh Street SW, Washington, DC 20590. Docket hours are 9:30 a.m. to 4 p.m. Monday through Friday.

FOR FURTHER INFORMATION CONTACT:

Samuel Daniel, Office of Rulemaking, NHTSA (202-366-4921).

\section{SUPPLEMENTAL INFORMATION:}

\section{Introduction}

The National Highway Traffic Safety Administration (NHTSA) is reviewing the safety needs of electrically powered vehicles (EVs) and considering possible rulemaking. The agency is taking this action in response to the increasing being given EVs as a means of achieving a cleaner and healthier environment. Due primarily to Federal and State requirements based upon environmental considerations, EVs appear likely to be introduced into the nation's motor vehicle fleet in significant numbers within the next 3 to 5 years.

NHTSA has twice previously reviewed the Federal Motor Vehicle Safety Standards (FMVSS) to determine their appropriateness for electric vehicles and published the findings in response to Congressional requirements. On those occasions, the agency concluded that all FMVSS are applicable to EVs although some of the crash avoidance standards may have to be revised because they contain text specifically addressing internal combustion engines or engine components. The agency also concluded that additional safety standards may be required by unique EV safety hazards. Most of these unique problems concern battery re-charging and the management of battery during a collision. No rulemaking was initiated by the agency following those earlier reviews because the prospect of significant numbers of EVs being produced was much more uncertain than it is now.

The purpose of this notice is to seek comments on any existing safety standards that may need to be amended to address EV safety problems, and any new standard that may need to be developed specifically 
for EVs. Under the National Traffic and Motor Vehicle Safety Act of 1966 (the Act), NHTSA is responsible for establishing safety standards for new vehicles and equipment to reduce motor vehicle accidents, deaths, and injuries. NHTSA is issuing this notice now because it wishes to have any necessary safety standards in place as soon as possible to support the safe introduction and operation of EVs. To delay rulemaking until significant production of EVs actually begins could not only fail to prevent avoidable safety problems, but also disrupt and impede the development and commercialization of EVs.

\section{Background}

The federal government has been involved in activities designed to stimulate the development and marketing of EVs since 1976 when the Electric and Hybrid Vehicle Research, Development, and Demonstration Act (Pub. L. 94-413) was enacted. Pursuant to that law, the Department of Energy (DOE) has sponsored the development of several hundred EVs and evaluated their performance over the past 10 years.

Public Law 94-413 also required the Department of Transportation (DOT) to conduct a study of the current and future applicability of the FMVSS and regulations to electric and hybrid vehicles. NHTSA published a study of EV saf ety requirements in 1978 entitled "Applicability of Federal MotorVehicle Safety Standards to Electric and Hybrid Vehicles." The study found that most existing FMVSS were suitable, although some containing reference to internal combustion engines or engine components would require modifications. The study also determined that new FMVSS may be necessary to address safety hazards unique to EVs. Specifically, it identified one standard addressed to isolating the electrical system from the occupant compartment to reduce the electric shock hazard, and another to the management of battery systems to reduce the potential for electrolyte spillage and explosion during a crash.

In 1988, the Altemative Motor Fuels Act (Pub. L. 100-494) was enacted. It included a requirement for a review by DOT, DOE, and the Environmental Protection Agency (EPA) of their respective regulations and a report identifying those rules or standards that are barriers to introduction of EVs into commerce. DOT's report to Congress in response to Public Law 100-494 is titled "Federal Regulations Needing Amendment to Stimulate the Production and Introduction of Electric/Solar Vehicles." The report, published in January 1990, reviewed EVs with respect to NHTSA safety regulations and procedures. The study concluded that $\mathrm{EV}$ performance (i.e., range and acceleration) has been the major obstacle to the introduction ofEVs into the marketplace and that federal safety standards have not been a significant obstacle. The initial cost of EVs has been another deterrent since it is not competitive with that of conventional intemal combustion engine vehicles due, in large part, to low production volumes. The review reached many of the same conclusions regarding the applicability of the FMVSS to EVs that were reported in 1978 in response to Public Law 94-413. The principal conclusions in the later report were that existing standards for brakes, tires, and windshield defrosting and defogging will probably need to be modified so that they are suitable as they apply to EVs. The report also concluded that new standards might be required, primarily in the area of crashworthiness, to address the safety problems that electric propulsion systems might pose during a collision. The three areas of concern were the potential for electric shock hazard, occupant contact with toxic electrolytes, and battery system explosion.

Interest in the suitability of Federal regulations as they affect EVs has increased in the last several years in response to the efforts of many major foreign and domestic automobile manufacturers to develop electrically powered passenger cars, trucks, and multi-purpose vehicles (MPV). The manufacturers are also preparing to build demonstration vehicles for evaluation in 2 to 3 years. However, at this time, detailed information concerning EV development by other than major manufacturers is difficult to obtain. Small manufacturers, and companies which convert conventional vehicles to electric power have built and tested prototype EVs in the recent past and made public their intent to market EVs in the near future. The electrical energy storage systems for the initial models planned for introduction in the next 2 years will primarily be advanced lead-acid batteries. Considerable research has been conducted on sodium- and zinc-based batteries as well as several other systems. It is anticipated that production EV's with these types of battery systems will be built in 4 to 6 years. 
The primary impetus for the introduction of large numbers of EVs into the U.S. marketplace is a regulation of the California Air Resources Board. Similar regulations are under consideration by other States. The California regulation requires that not less than two percent of a manufacturer's sales in the State (roughly 40,000 vehicles total) must be zero emission vehicles (ZEVs), beginning in model year 1998. This requirement will increase to 10 percent or roughly $200,000 \mathrm{ZEVs}$ beginning in model year 2003 . The definition of a ZEV is a vehicle that emits no exhaust or evaporative emission of any kind. Currently, the electric vehicle is the only vehicle which meets these requirements. The only other altemative fuel expected to meet the ZEV requirements is hydrogen fuel cells. However, this technology is still in the research and development stage.

\section{Potential Problem Areas and Possible Solutions}

As stated earlier, the purpose of this notice is to solicit comments to help NHTSA determine whether and how the existing FMVSS should be modified to improve their suitability for EVs, and to determine the types of any new standards that may be developed to address unique EV safety hazards.

Information and comments are requested from users and suppliers, manufacturers, government agencies, and all other interested parties. Commenters should bear in mind that the Federal motor vehicle safety standards established by NHTSA under the Vehicle Safety Act are performance-oriented standards. In commenting on a particular option or in responding to a particular question, commenters are requested to provide all relevant and factual information to support their conclusions or opinions. This should include, but not be limited to, statistical data, estimated costs and benefits, necessary manufacturer lead times, and the availability of technology. Accident data should also be provided including data related to vehicle fires, injuries, fatalities. The sources of such information should be identified.

NHTSA emphasizes that this is an advance notice of proposed rulemaking. If the agency were ultimately to issue a final rule, it would do so only after first issuing a notice of proposed rulemaking seeking further comments.

\section{A. Modifications to FMVSS to Improve Suitability}

The FMVSS are organized into three main categories covering crash avoidance, crashworthiness, and post crash factors. Based on studies and reviews of the FMVSS's concerning their suitability for EVs, NHTSA has concluded that EVs should comply with the intent or purpose of all existing FMVSS. Several standards may require modifications, however, as some aspects of them are premised on types of technology, e.g., internal combustion engines, not found in EVs. Specific comments are sought on how these standards might be modified. In addition, compliance of EVs with several existing safety standards is difficult, if not impossible, due to the characteristics of current EV designs, e.g., range limitations, lack of on-board heat source, limited auxiliary power. Specific comments are sought on whether the performance requirements of these standards should be reduced for EVs, and, if so, what performance requirements would be appropriate. These issues are discussed in greater detail below.

\section{Crash Avoidance Standards}

1. FMVSS No. 102, Transmission Shift Lever Sequence, Starter Interlock, and Transmission Braking Effect

EVs with multi-speed transmissions that are not equipped with regenerative braking may have difficulty complying with the transmission braking provision of this Standard No. 102 which requires transmission braking effects at speeds under $25 \mathrm{mph}$ for automatic multi-speed transmissions.

The questions for which NHTSA seeks comment are:

(a) Should EVs be required to comply with the transmission braking effect requirements of Standard No. 102 ?

(b) What percentage of EVs are likely to be equipped with multi-speed automatic transmissions? 


\section{FMVSS No. 103, Windshield Defrosting and Defogging Systems}

One provision of Standard No. 103 requires the defrosting and defogging system of a vehicle to be capable of melting specific amount of windshield ice within a specified time period after allowing a time period for engine warm-up. In the past, some EVs equipped with an on-board combustion heater have used them for defrosting and defogging systems, although there is no record of an EV meeting the requirements of this portion of the standard. However, for EVs, the reference to engine warm-up is meaningless and may require revision.

The questions for which NHTSA seeks comments are:

(a) How should Standard No. 103 be modified to reflect the fact that an engine warm-upperiod may not be needed and a warm-up time period for a combustion heater may need to be substituted?

(b) Should the requirements of Standard No. 103 be revised for EVs? If so, what requirements for EV defrosting and defogging would be appropriate? What effect would these modifications to Standard No. 103 have on EV safety?

3. FMVSS No. 105, Hydraulic Brake Systems

Standard No. 105 specifies requirements for hydraulic service brakes and associated parking brake systems. One of the standard's provisions is that the vehicle be placed in neutral for some of the tests. For EVs with direct drivesystems and/or regenerative braking this test procedure may be difficult to comply with.

The questions for which NHTSA seeks comment are: do the test procedures of Standard No: 105 need to be modified for EVs equipped with regenerative braking and/or direct drive transmissions? If so, what should the modifications be?

\section{Crashworthiness Standards}

\section{FMVSS No. 204, Steering Control Rearward Displacement}

Standard No. 204 specifies the maximum rearward displacement of the steering control system during a $30 \mathrm{mph}$ rigid barrier collision. It is anticipated that EVs converted from internal combustion engine (ICE) vehicles may have problems complying with Standard No. 204 and some, if not all, of the crashworthiness standards that contain the rigid barrier crash test procedure. The converted EVs are usually at least 10 percent heavier than the ICE vehicle from which they were derived. This is potentially significant because the weight increase may result in more overall deformation of the EV during the crash test. Increased overall frontal deformation would increase the likelihood that the requirements of Standard No. 204 would not be met. For EVs having difficulty meeting the requirements of this standard, NHTSA notes that the Vehicle Safety Act provides that a manufacturer may apply for a 2-year temporary exemption for up to 2,500 vehicles per year on the basis that an exemption would facilitate the development and field evaluation oflow-emission motor vehicles.

The question for which the agency seeks comments is: should NHTSA consider seeking an amendment of the Vehicle Safety Act that would increase the number of vehicles that the exemption covers per year and would lengthen, from 2 years to 3 years, the maximum term allowed for exemptions greater on the basis of substantial economic hardship? These amendments might facilitate the production of these lowemission vehicles.

\section{FMVSS No. 208, Occupant Crash Protection}

Standard No. 208 places limits on the head, thorax, and leg impact responses of test dummies placed in front outboard seats during a $30 \mathrm{mph}$ rigid barrier crash test. Many EVs that are designed and 
built as EVs (and not converted from ICE to electric propulsion) are small and light. There is concern that many such vehicles may have problems meeting the requirements of Standard No. 208 due to limited crash energy management capability. As previously stated, EVs converted from ICE vehicles may have problems complying with the standards that contain barrier crash test procedures because of the weight increase that often occurs as a result of the conversion. Previous studies of the suitabilkity of the FMVSS for EVs have concluded that compliance with the barrier crash test standards may present problems, but is practicable and necessary for ssafety. There are few crash test data available on late model EVs with which to objectively assess the stability of those existing vehicles to meet the requirements of the barrier crash test standards. For EVs needing significant modifications to meet the requirements of Standard No. 208, use of the temporary exemption procedure as an interim measure might be appropriate.

The questions for which the agency seeks comment are:

(a) See the question under paragraph 5 above.

(b) If the number of exempted vehicles per year were increased for EVs, what would be the overall effect on the safety for occupants of these vehicles?

\section{Post Crash Standards}

6. FMVSS No. 301, Fuel System Integrity

Standard No. 301 specifies requirements for the integrity of motor vehicle fuel systems by limiting fuel spillage and fuel spillage rates for vehicles after rollover, frontal barrier, and rear moving barrier tests. Since many EVs may contain combustion heaters with a tank and lines, the agency concluded in its previous studies of the suitability of the FMVSS for EVs that EVs should meet the requirements of Standard No. 301. The fire and explosion hazard that results from spilled fuel may be greater for EVs because of the large number of ignition sources compared to ICE vehicles. As to battery liquids, although most electrolytes are not nearly as likely to ignite, they are generally highly corrosive and toxic.

The questions for which the agency seeks comment are:

(a) Should EVs comply with the Standard No. 301 as it is presently written, or should it be modified for EVs? If Standard No. 301 should be amended for EVs, what should those modifications be?

(b) Should requirements similar to the fuel spillage and fuel spillage rate requirements of Standard No. 301 be adopted to regulate the spillage of liquid electrolyte?

\section{B. New Standards to Address Potentially Unique Electric Vehicle Safety Hazards}

New federal EV safety standards may be needed to address potential safety hazards associated with routine servicing of the vehicles, re-charging of the battery systems, crashworthiness and crash avoidance problems. routine service and re-charging safety hazards can result from the possibility of a malfunction of the propulsion system such as a short circuit. Unique crash avoidance safety hazards may result primarily from the operational characteristics of EVs. For example, most of the drive motors make very little noise compared to internal combustion engines. This may result in a safety hazard for pedestrians, particularly when an EV is backing up. Also, acceleration performance of some EVs, which has been poor in comparison to conventional vehicles, may cause these vehicles to pose a safety hazard when operating on limited access roads and while merging into high speed traffic. Crashworthiness safety hazards unique to EVs may be primarily associated with the possibility that battery system components, chemicals, and electrical energy may not be contained during a collision. DOE adopted several crash avoidance and crashworthiness safety regulations (10 CFR part 475) to address unique EV safety hazards. EVs purchased by DOE under its development and demonstration program mandated by Public Law 94-413, The Electric and Hybrid Vehicle 
Research, Development, and Demonstration Act, were required to comply with these regulations. The DOE safety regulations for the basis for several questions that this notice asks below.

1. New Regulations To Address Safety Hazards Associated with Maintenance and Re-Charging The questions for which the agency seeks comment are:

(a) Should NHTSA consider rulemaking that would standardize cables, connectors, receptacles, transformers, and procedures involved in the re-charging of the traction or propulsion battery systems? If so, have standards for these devices and procedures been adopted by the U.S. Military, Society of Automotive Engineers (SAE), American National Standard/Electronic Industries Association (ANSI), or any other organization that would adequately reduce the recharging safety hazards and thus be suitable to serve as a basis for NHTSA rulemaking?

(b) Should a procedure be standardized through NHTSA rulemaking for disabling the main drive power circuitry during routine EV maintenance in order to minimize the danger of shock, explosion or fire being caused by carelessness or inexperience? If so, are there currently regulations in existence that effectively address this problem and thus would be suitable to serve as a basis for NHTSA rulemaking?

2. New Regulations To Address Unique Crash Avoidance Safety Hazards

The questions for which the agency seeks comment are:

(a) Should NHTSA consider a requirement for an audible signal that operates when an EV's transmission is in reverse? Such a signal would increase the likelihood that any pedestrian in the vicinity of a backing EV is aware of the vehicle's movements.

(b) Should NHTSA consider rulemaking that would require battery vents to have flame barrier provisions to inhibit battery explosions?

(c) Should NHTSA develop a regulation to require venting of the battery compartment in order to minimize the safety hazards that result from an accumulation of explosive gases?

(d) Should the agency consider developing a standard to require that EV's have a device that positively disconnects the battery and that is operable from the normal operator position?

(e) Should lower bound limits be placed on the accelerator and velocity performance of EVs to ensure that they have some minimum capability of operating in a traffic mix that includes conventional vehicles?

(f) Since some EVs may have a single speed transmission which wouldallow the vehicles to operate at the same speed in reverse as they do in forward, should NHTSA consider a regulation that places a limit on maximum reverse speed? If so, what should this speed be?

(g) For EVs with a single speed transmission (Standard No. 102 applies to multi-speed transmissions), should NHTSA consider a regulation to require these vehicles to have a braking effect at any speed less than $25 \mathrm{mph}$ ? If so, what should the declaration rate be? Would the effects regenerative braking, for vehicles so equipped, be enough to satisfy this requirement?

(h) Should the agency consider a regulation requiring EVs to have a warning device in the direct forward view of the driver, that operates in the event of an electrical malfunction in the propulsion system?

3. New Standards To Address Potentially Unique EV Crashworthiness Safety Hazards

The questions for which the agency seeks comment are:

(a) Should NHTSA consider issuing a standard to require that the electric propulsion circuit be electrically isolated from the other conductive portions of the vehicle sufficiently to prevent injury due to a person's contacting any portion of the electric propulsion circuit while in contact with other portions of the vehicle? 
(b) Should NHTSA require that EVs be capable of complying with the requirements of Standard No. 208, Occupant Crash Protection, and Standard No. 301, Fuel System Integrity, without battery material intruding into the vehicle's occupant comparment?

(c) Should NHTSA consider rulemaking to require that all battery materials remain outside the occupant compartment but inside the vehicle during a barrier crash test at a speed less than 30 mph? If so, what crash test speeds should be considered?

(d) Should NHTSA consider requirements to limit the spillage and spillage rate of liquid electrolytes during a barrier collision with requirements similar to the fuel spillage and fuel spillage rates specified in Standard No. 301, Fuel System Integrity?

(e) Should NHTSA consider requirements to limit exposure to battery elements that operate at temperatures in excess of specified value? If so, what should the compliance test for such a requirement be?

(f) Should NHTSA consider developing a standard to require EVs to have a device which automatically disconnects the propulsion battery circuitry in the event of a high energy crash?

\section{Rulemaking Analyses}

\section{Executive Order 12291 (Federal Regulation) and DOT Regulatory Policies and Procedures}

This advance notice of proposed rulemaking is not subject to Executive Order 12291.

However, the subject matter of the advance notice is considered "significant" under DOT's regulatory policies and procedures. The notice concerns a matter of substantial public interest. NHTSA believes that most, if not all, of the EVs being built for demonstration purposes incorporate features that address some or all of the potential safety problems discussed in this notice. The fact greatly reduces the potential cost of compliance with whatever standards NHTSA may ultimately adopt. Based on available information, the agency believes that the cost associated with various potential requirements discussed in this notice might not be significantly more than those now being incurred by manufacturers of existing electrically powered vehicles if no standards were developed. However, the impacts of this action can only be estimated with a significant degree of precision when the agency decides which, if any, of the various requirements will form the basis for a rule. Therefore, a full preliminary regulatory evaluation (PRE) for this notice has not been prepared. One of the purposes of this advance notice is to seek comments and information from the public on the costs, benefits, and feasibility of the various options and thus provide the basis for a more definitive evaluation at the next stage of this proceeding.

\section{Executive Order 12612 (Federalism)}

This action has been analyzed in accordance with the principles and criteria contained in Executive Order 12612 "Federalism" and it has been determined that the advance notice does not have sufficient federalism implications to warrant the preparation of a Federalism Assessment.

\section{National Environmental Policy Act}

The agency will review proposals for rulemaking that arise from this advance notice to determine whether they would have a significant effect upon the environment for the purposes of the National Environmental Policy Act.

\section{Regulatory Flexibility Act}

Review of this advance notice under the Regulatory Flexibility Act is not required because the Act does not apply to an advance notice of proposed rulemaking. Should the agency decide to proceed with a notice of proposed rulemaking, review of that notice under the Regulatory Flexibility Act will be made at that time. 


\section{COMMENTS:}

submitted.

NHTSA solicits public comments on this notice. It is requested but not required that 10 copies be

All comments must not exceed 15 pages in length, 49 CFR 553.21. Necessary attachments may be appended to these submissions without regard to the 15-page limit. This limitation is intended to encourage commenters to detail their primary arguments in a concise fashion.

If a commenter wishes to submit certain information under a claim of confidentiality, three copies of the complete submission, including purportedly confidential business information should be submitted to the Chief Counsel, NHTSA, at the street address given above, and seven copies from which the purportedly confidential information has been deleted should be submitted to the Docket Section. A request for confidentiality should be accompanied by a letter setting forth the information specified in the agency's confidential business information regulation, 49 CFR part 512.

All comments received before the close of business on the comment closing date indicated above will be considered, and will be available for examination in the docket at the above address both before and after that date. To the extent possible, comments filed after the closing date will also be considered. Comments on the notice will be available for inspection in the docket. NHTSA will continue to file relevant information as it becomes available in the docket after the closing date and it is recommended that interested persons continue to examine the docket material.

Those persons desiring to be notified upon receipt of their comments in the docket should enclose a self-addressed, stamped postcard in the envelope with their comments. Upon receiving the comments, the docket supervisor will retum the postcard by mail.

A regulatory information number (RIN) is assigned to each regulatory action listed in the United Agenda of Federal Regulations. The Regulatory Information Service Center publishes the Unified Agenda in April and October of each year. The RIN contained in the heading of this document can be used to cross reference this action with the Unified Agenda.

Authority: 15 U.S.C. 1392, 1401, 1407, delegations of authority at 49 CFR 1.50 and 501.8.

Issued: December 23, 1991.

Barry Felrice

Associate Administrator for Rulemaking.

[FR Doc. 91-30965 Filed 12-26-91: 8:45 am]

BILLING CODE 4910-59-M 


\section{Appendix C. Industry Standards and Recommended Practices Potentially Applicable to EVs}

Society of Automotive Engineers (SAE)

SAE J556 [same as J1292], Automobile, Truck, Truck-Tractor, Trailer, and Motor Coach Wiring [1]. This is a SAE recommended practice related to the primary wiring distribution system hamesses to automotive, truck, and similar type vehicles. It covers the areas of performance, operating integrity, efficiency, economy, and uniformity for wiring systems of less than $50 \mathrm{~V}$.

SAE J537, Storage Batteries [2]. This standard applies to lead-acid types of batteries. However, it can provide some guidance on establishing rating practices for advanced batteries such as $\mathrm{Na} / \mathrm{S}$. This standard establishes the practices to be used in the charging and discharging of batteries, cold crank tests, and vibration tests. These standards could be used as they are, or similar practices could be developed for other battery technologies.

Insititute of Electrical and Electronic Engineers (IEEE)

IEEE 11-1980, Standard for Rotating Electric Machinery for Road and Rail Vehicles [3]. This standard provides for special conditions which may be invoked by agreement between manufacturer and purchaser such as high ambient temperature and variation of performance with voltage.

American National Standard/Electronic Industries Associaton (ANSI/EIA)

ANSIEIA RS-336-68, Color Coding for Chassis Wiring [4]. This standard establishes guidelines for the colors to be used in electrical wiring, based on the component and could be extended or modified for use by EV developers.

National Electrical Manufacturers Association (NEMA)

NEMA 107-1987, Methods of Measurement of Radio Influence Voltage [RIV] of High Voltage Apparatus [5]. This standard covers the measurement of radio influence voltage and it deals with a frequency range of 0.015 to 30 megahertz.

NEMA MG 3-1, Sound Level Prediction for Installed Rotating electrical machines. This is an infornational booklet that provides a method for predicting sound pressure levels in industrial and commercial areas [6]. Although this methodology, as written, applies to rooms and buildings, the principles used can be extrapolated to predict sound levels in automobiles. If the calculated sound level is low it could provide reason to establish a need for a backup waming signal for EVs.

National Electric Code (NEC)

National Electric Code [NEC] Article 240, Over-current Protection [7]. This standard provides for these situations: arcing of suddenly moving parts when disconnecting or grounding, enclosures in damp or wet locations, circuit breakers and fuses. This standard provides for voltages under 600 Volts, which would make them applicable to EVs. 
MIL-STD-810C [8] establishes a set of standards for environmental test methods. Pertinent testing procedures are set forth for verifying worthiness of performance in several environments which include: low pressure, high and low temperature, temperature shock, solar radiation, rain, humidity, fungus, salt fog, dust, leakage immersion, acceleration, vibration, and shock. All of these standards could be somewhat useful to testers in efforts to increase the durability and safety of the EVs.

MIL-STD-882B [9], System Safety Program Requirements provides little guidance on standards themselves but might help guide risk assessment activities. This document "provides uniform requirements for developing and implementing a system safety program of sufficient comprehensiveness to identify the hazards of a system and to impose design requirements and management on controls to prevent mishaps by eliminating hazards or reducing the associated risk to a level acceptable to the managing activity."

MIL-STD-285, Attenuation Measurements for Enclosures, Electromagnetic Shielding, for Electronic Test Purposes, Method of [10]. This standard establishes a testing method for attenuation characteristics of electronic shielding enclosures for the frequency range of 100 kilocycles to 10,000 megacycles.

MIL-STD-H-46855, Human Engineering Requirements for Military Systems, Equipment and facilities [11]. This standard deals with the application of human engineering to military equipment and systems. It specifies broad and general recommendations on development, implementation and even failure analysis with regard to human engineering.

MIL-STD-826 has been changed to MIL-STD-461, Electromagnetic Emission and Susceptibility requirements for the Control of Electromagnetic Interference [12] and MIL-STD-462, Electromagnetic Interference Characteristics, Measurement of [13]. These standards provide a methodology for testing for malfunctioning and degradation resulting from electrical interference from signals of different kinds. 


\section{References}

1. SAE J556 [same as SAE J1292], Automobile, Truck, Truck-Tractor, Trailer, and Motor Coach Wiring, 1981.

2. SAE 537, Storage Batteries, 1986.

3. IEEE 11-1980, Standard for Rotating Electric Machinery, 1980.

4. American National Standard, Electronic Industries Association, Color Coding for Chassis Wiring, ANSI/EIA RS-336-68, July 26, 1968.

5. NEMA 107, Method of Measurement of Radio Influence [RIV] of High Voltage Apparatus, 1987.

6. NEMA MG-3, Sound Level Prediction for Installed Rotating Electrical Machines, 1974.

7. NEC 240, Overcurrent Protection, 1987.

8. Military Standard, Environmental Test Methods, MIL-STD-810C, March 10, 1975.

9. Military Standard, System Safety Program Requirements, MIL-STD-882B, March 30, 1984.

10. Military Standard, Attenuation Measurements for Enclosures, Electromagnetic Shielding, For Electronic Test Purposes, Method of, MIL-STD-285, 1956.

11. Military Standard, Human Engineering Requirements, MIL-STD-46855, 1984.

12. Military Standard, Electromagnetic Emission and Suceptibility Requirements, MIL-STD-461 (was 826), 1980.

13. Military Standard, Electromagnetic Interference Charateristics, Measurement of, MIL-STD-462 (was 826), 1967. 